\title{
Postpartum intra-uterine contraceptive device utilization among mothers who delivered at debre tabor general hospital: cross sectional study design
}

\begin{abstract}
Introduction: Rapid population growth is a major concern of many states globally including our country Ethiopia. The intrauterine device (IUD) is a long term reversible contraceptive method that is suitable for women of all reproductive ages, and represents the most cost effective reversible method for preventing unwanted pregnancies. However, its utilization in Ethiopia is very low as compared to other contraceptive methods.
\end{abstract}

Objective: To assess postpartum intra-uterine contraceptive device utilization among mothers who delivered and seek immunization service at DTGH, North Central Ethiopia.

Methods: Facility based cross sectional study design was conducted from November 17, 2017, to January 01, 2018. A total of 182 respondents were interviewed. Systematic random sampling procedure was used to select each eligible study unit as a participant. Data were collected by Midwifery professionals through face to face interview through structured questionnaires under supervision. The data collectors and supervisors were trained prior to data collection. Pretest was conducted on $5 \%$ of the study population to check for the accuracy of tools. Confidentiality was also protected by making the data collection procedure anonymous. The association between dependent and independent variables were determined by descriptive statistics of chi square test using SPSS version 20.0 software and p-values of $<0.05$ were considered as statistically significant.

Result: One hundred eighty two mothers were interviewed to assess IUCD utilization after giving birth at DTGH with a response rate of $97 \%$. Only 6 respondents $(3.3 \%)$ are currently using IUCD after giving birth to 9 months of their post partum period. Acceptances of IUCD with P of 0.004 and Reasons for refusal of IUCD with P value of 0.035 were some of statistically associated variables for utilization of PP IUCD.

Conclusion: PP IUCD utilization in the study area is low as compared to other similar studies (3.3\%). There are major discrepancy between acceptance level (37.91\%) and PP IUCD utilization. Responsible bodies should address the reason for this major discrepancy to minimize the gap.

Keywords: prevalence, utilization, acceptance, and factors
Volume 4 Issue 5 - 2020

\author{
Haymanot Hagos,' Dawit Tiruneh, ${ }^{2}$ Worku \\ Necho, ${ }^{3}$ Shemelis Biru ${ }^{4}$ \\ 'Clinician in Midwifery, Department of Obstetrics and \\ Gynecology, Debre Tabor Hospital, Ethiopia \\ ${ }^{2}$ Lecturer of Maternal and Reproductive Health, Department of \\ Midwifery, College of Health sciences, Debre Tabor University, \\ Ethiopia \\ ${ }^{3}$ Lecturer of Maternal Health in Nursing, Department of \\ Nursing, College of Health sciences, Debre Tabor University, \\ Northwest Ethiopia \\ ${ }^{4}$ Lecturer of Clinical Midwifery, Department of Midwifery, \\ College of Health Sciences, Debre Tabor University, Ethiopia
}

Correspondence: Dawit Tiruneh, Lecturer of Maternal and Reproductive Health, Department of Midwifery, College of Health sciences, Debre Tabor University, Northern west Ethiopia, Ph.D student in Public health at Haramaya University, Eastern Ethiopia, Tel +251920806931,

Email dawit2h2005@gmail.com

Received: July 30, 2020 | Published: October 20, 2020
Abbreviations: COC, combined oral contraceptives; CPR, contraceptive prevalence rate; DTGH, debre tabor general hospital;EC, emergence contraceptive; EDHS, ethiopian demographic and health survey; FP, family planning; GC, gregorian calendar; IUCD, intra uterine contraceptive device; LARC, long acting reversible contraceptives; PNC, postpartum care; PPP, postpartum period; SPSS, statistical package for the social science; WHO, world health organization

\section{Background}

The intrauterine device (IUD) is a long term reversible contraceptive method that is suitable for women of all reproductive ages, and represents the most cost effective reversible method for preventing unwanted pregnancies. ${ }^{1}$ IUCDs work mainly by preventing fertilization of the egg by the sperm. ${ }^{2}$ Now a time, more women are being encouraged to deliver in facilities, providing increased opportunity for immediate postpartum insertion of an intrauterine contraceptive device (IUCD). Interest has also been renewed in postpartum family planning (PPFP) services in light of recent research that supports the health benefits of pregnancy spacing or limiting for the mother and baby. A mother can have insertion of PPIUCD within 10 minutes after placental expulsion, insertion before closing the uterine incision, insertion from 10 minutes up to 48 hours postpartum before discharge them and anytime four weeks or later after childbirth if she is not pregnant. ${ }^{3}$ Women throughout the world have found the intrauterine contraceptive device (IUCD) to be safe and convenient method of contraception. It is estimated that more than 100 million women are using IUCDs. Women who use IUCD are among the most satisfied contraceptive users, with studies in the U.S. showing satisfaction rates of $99 \%$ for IUCD user compared to $91 \%$ for pills users. Careful screening and counseling are essential for successful use of an IUCD. The client must know how the IUCD works, what the side effects might be, and what are the warning sign as well. The IUCD does not affect breastfeeding, safe for AIDS clients controlled with Antiretroviral Therapy (ART) and a good choice for women who cannot use Combined Oral Contraceptive (COC). The latest scientific evidence shows that the Copper T 380A (Cu-T 380A) is effective for at least 12 years. Good infection prevention practices are necessary during insertion and removal to safeguard the client. ${ }^{4}$ 
By region, contraceptive prevalence rate ranges from 2 percent in Somali to 56 percent in Addis Ababa. Contraceptive use increases with women's education and household wealth. For instance, 31 percent of women with no education are using a contraceptive method compared with 55 percent of women with more than a secondary education. Women with no living children (30percent) and those with five or more children (28 percent) are the least likely to use any method of contraception. Among sexually active unmarried women, 58 percent are currently using a contraceptive method: 55 percent are using a modern method and 3percent are using a traditional method. The most commonly used methods among sexually active unmarried women are injectables (35percent), implants (11percent), the male condom, and emergency contraception (4percent each). ${ }^{5}$ Rapid population growth is a major concern of many states globally including our country Ethiopia. Many studies showed that a baby born after a short birth interval has increased chances of being born preterm, small for gestational age and death during newborn period or childhood. A woman who becomes pregnant too quickly following a previous birth or spontaneous or induced abortion faces higher risks of anemia, abortion, premature rupture of membranes and maternal mortality. ${ }^{6} \mathrm{~A}$ study in India showed that $65 \%$ of women in the first year postpartum have an unmet need for family planning. Only $26 \%$ of women are using any method of family planning during the first year postpartum. Partially breastfeeding or not breastfeeding women may resume menses within 4-6 weeks of delivery and first ovulation may occur as early as 45 days postpartum thereby increasing the risk of pregnancy soon after childbirth. ${ }^{6}$

The popularity of immediate post-partum IUCD insertion in countries as diverse as China, Mexico, and Egypt support the feasibility of this approach. Expulsion rates appear to be higher than with interval insertion. As result, early follow-up may be important in identifying spontaneous IUCD expulsions and managing common side effects and complications of IUCD such as heavy vaginal bleeding, abdominal cramping, missing of strings, uterine perforation, PID and rarely ectopic pregnancy. ${ }^{7}$ The current contraceptive use by married women showed wide variation across regions, ranging from $34 \%$ in Tigray to $61 \%$ in Amhara. Younger, nulliparous, and poorer women were less likely to use contraceptives than their counterparts. Injectable contraceptive was the most frequently used method, adopted by $78 \%$ of all FP users. The second most frequently used method was implants, which were used by $16 \%$ of FP users. The remaining $6 \%$ of users adopted pills $(4 \%)$, IUCD $(1 \%)$ and others $(<1 \%)$. Nearly four in five of the women were using short-term FP methods. Men involved in FP use appeared to be supportive in some cases, although there was a long way to go in increasing their awareness about and support of FP to increase and sustain FP use in the community. ${ }^{8}$ With the copper IUCD, menstrual pain and bleeding may increase at first. Bleeding between periods may occur. Both effects are common in the first few months of use. Pain and heavy bleeding usually decrease within 1 year of use. The hormonal IUCDs may cause spotting and irregular bleeding in the first 3-6 months of use. The amount of menstrual bleeding and the length of the menstrual period usually decrease over time. Menstrual pain also usually decreases. A few women also may have side effects related to the hormones in these IUCDs. These side effects may include headaches, nausea, depression, and breast tenderness. ${ }^{2}$

A comparison of results from the past EDHS surveys reveals that the CPR among currently married women in Ethiopia has increased steadily from 8 percent in 2000 to 36 percent in 2016. The largest increase is observed in the use of injectables which increased from 3 percent in 2000 to 23 percent in 2016. The use of implants has also increased during the same period from less than 1 percent in 2005 to 8 percent in 2016. The percentage of married women with unmet need for family planning has been declining over time, from 37 percent in 2000 to 22 percent in $2016 .{ }^{5}$ Therefore the purpose of this research aims to describe barriers for low utilization of post partum Intra uterine contraceptive methods in the study area. Population growth is a major public health concern globally. Uncontrolled fertility which does not go in line with economic development in sub-Saharan African countries has major demographic entrapments. The issue of fertility regulation is important on both health and social grounds. Many studies showed that children born to very close intervals are at increased risk of sickness, adverse pregnancy outcomes and deaths. The percentage of the demand for family planning that is satisfied with modern contraceptive methods has increased substantially from 14 percent in 2000 to 61 percent in 2016. But acceptance and utilization of IUCD is very low in Ethiopia. IUCD is one of the most highly effective, convenient, and cost effective FP method that does not interfere with breastfeeding. But its utilization in Ethiopia is extremely very low, which is as low as 2 percent. $^{5}$ The findings from the study will be used by decision makers in development of strategies to strengthen the uptake of IUD as a long term method of contraception that have a significant impact on CPR. This will help them recognize its importance for the reduction of unintended and short-interval pregnancy. In addition, the findings of this research will serve as a base line for other researchers for further investigation. It also helps administrators and health care providers in DTGH to refine their ways of family planning service delivery system to maximize the utilization of IUCD. Therefore the aim of was to assess postpartum intra-uterine contraceptive device utilization and associated factors among mothers who delivered at Debre Tabor General Hospital, North Central Ethiopia in 2017.

\section{Method and materials}

Study design: Facility-based cross-sectional study design conducted at Debre Tabor General Hospital, Northwest Ethiopia, November 17, 2017, to January 01, 2018. Study area and period: This study was conducted in Debre Tabor General Hospital in Debre Tabor town from November 10/2010 to December 25/2010 E.C. Debre Tabor town is one of the Zonal towns in the Amhara national regional state of Ethiopia. It is located $103 \mathrm{Km}$ away from Bahir Dar and $666 \mathrm{Km}$ away from Addis Ababa the northwest direction. The town has four kebeles and a total population of 87,627, of which 41,957 are men and 45,670 women. Among these 14,462 of the population are women in the reproductive age group (15-49 years). There is one hospital, three health centers, three private clinics and four Health Posts in the town. The town has a latitude and longitude of $11^{\circ} 51^{\prime} \mathrm{N} 38^{\circ} 1^{\prime} \mathrm{E} 11,850^{\circ} \mathrm{N}$ $38.017^{\circ} \mathrm{E}$ with an elevation of 2,706 meters above sea level. In this Town there are governmental and non-governmental health institutions: $3 \mathrm{HC}, 1$ General hospital and 01 private clinic.

Source population: All mothers of reproductive age group (15-49 years) during their post partum period in Debre Tabor town in 2017

Study population: All sampled mothers in reproductive age group (15-49 years) who have delivered in Debre Tabor General Hospital during the study period in 2017.

\section{Inclusion criteria}

I. All reproductive age group mothers (15-49 years) who delivered and seek immunization services in DTH and willing to participate were included in the study.

II. Mothers who live in Debre Tabor Town for at least six months. 


\section{Exclusion criteria}

I. Mothers with known mental illness

II. Mothers who are severely ill to interview.

III. Mothers after nine months of their post partum period were excluded.

Sample size: Sample size was calculated using single proportion formula with the assumption of $22 \%$ of the participants who had actual PPIUD insertion within 48 hours of delivery from a study conducted among Mothers Delivered at Public Health Facilities of Sidama Zone, South Ethiopia, ${ }^{11}$ at $95 \%$ confidence interval, the margin of error is taken as 0.05

$$
\begin{aligned}
& \mathrm{n}=\mathrm{z}^{2} \mathrm{p}(1-\mathrm{p}) / \mathrm{d}^{2} \\
& =(1.96)^{2} 0.22(1-0.22) /(0.05)^{2}=264
\end{aligned}
$$

\section{Where}

$\mathrm{n}=$ number of the study subjects (sample size)

$\mathrm{Z}=$ is standardized normal distribution value at the $95 \%$ confidence level (1.96)

$$
\begin{aligned}
& \mathrm{p}=22 \% \text { of population proportion with actual utilization of PPIUCD } \\
& \mathrm{d}=\text { the margin of error taken }(0.05 \text { taken }) \text { rate }=5 \% \\
& \text { Since the source population is }<10,000 \\
& \mathrm{NF}=[\mathrm{n} /(1+(\mathrm{n} / \mathrm{N})], \mathrm{N}=558 \\
& \mathrm{NF}=[164 /(1+264 / 558)] \\
& \mathrm{NF}=179
\end{aligned}
$$

Assuming a response rate of $95 \%$, thus, 5\%non-response rate and the calculated sample size will be $=(179+5 \%$ non-response rate $)=$ 188.

Sampling procedure: Respondents who were mothers of reproductive age group women (15-49 years) who were delivered in DGTH during data collection period. The study was conducted in PNC and immunization units of DGTH. Then systematic sampling procedure was used to select each eligible study unit by the formula $\mathrm{K}=\mathrm{N} / \mathrm{n}=558$ / $188=2.97$ which is approximately 3 . Every third and eligible mothers were selected through calculation. Hence, the selected mother who needed contraceptive method and waiting for discharge were selected for the interview.

Dependent variables: Postpartum IUCD utilization: Binary response (Yes/No).

Independent variables: Age, marital status, education, occupation, religion, parity, alive births, birth intervals, duration of post partum period, Time of insertion, fertility desires, source of information contraceptives, FP counseling, previous FP use, Partner influence, availability of contraceptives, accessibility of services, side effects, reasons for refusal, misconception

Operational definitions

I. Post partum period: a period that extends from birth to nine months after giving birth for this study

II. PP IUCD utilization: mothers who have got IUCD inside the uterus within $48 \mathrm{hrs}$ and after $6-9$ months of their postpartum period.

\section{Data collection procedures}

Data were collected using a structured interview by using modified semi structured questionnaire that was adopted from similar study. ${ }^{10}$ Data were collected by two trained Midwifery professionals through face to face interview from November 10/2010 to December 25/2010 E.C. The data collectors and supervisors were trained before the actual data collection to prepare them for respectful approach, understand the objective of the study and client's ethical issue.

\section{Data quality control}

Questionnaires were prepared in English language prior to the actual data collection period. Data tools were pretested at DTGH one week prior to data collection by conducting on $5 \%$ of the study population to check for the accuracy of responses, language clarity, and appropriateness of the tools. Necessary modification was made before being applied on the study participants. Before data collection, explanation about the questionnaire was given for study participants to understand the objectives of the study and to clear each of the questions in the questionnaire before starting interviewing. The supervisor was routinely checked up for completeness and consistency of the data and necessary feedback was offered on the next day before data collection.

\section{Data management and analysis}

The data were collected and coded first and then checked for completeness and internal consistency then it was sorted, grouped and stored on the tally sheet by using computer. The analyzed data were presented using descriptive statistics of frequency and percentage. Tables were prepared and presented using computer. The association between dependent and independent variables were determined by descriptive statistics of chi square test using SPSS version 20.0 software and p-values of $<0.05$ was considered as statistically significant.

\section{Results}

\section{Socio-demographic characteristics}

One hundred eighty two mothers were interviewed to assess IUCD utilization after giving birth at DTGH with a response rate of $97 \%$. Majority $47.8 \%$ respondents have age group of 25-29 years. Regarding to marital status, $146(80.2 \%)$ respondents are married and $86.8 \%$ are orthodox religion followers. Regarding to their educational status, $30.2 \%$ respondents have completed secondary level of education. $30.8 \%$ respondents are house wives (Table 1 ).

Table I Distribution of socio-demographic variables of respondents from Nov. I0/2010 to Dec.25/2010 E.C at DTGH in Amhara region

\begin{tabular}{lll}
\hline Study variables & Frequency & Percent \\
\hline Age $($ yrs $)<25$ & 30 & 16.5 \\
$25-29$ & 87 & 47.8 \\
$30-34$ & 31 & 17 \\
35 and above & 34 & 18.7 \\
Marital status & & \\
Married & 146 & 80.2 \\
Divorce & 15 & 8.2 \\
Widowed & 6 & 3.3 \\
Single & 15 & 8.2 \\
\hline
\end{tabular}


Table continue

\begin{tabular}{lll}
\hline Study variables & Frequency & Percent \\
\hline Religious status & & \\
Orthodox & 158 & 86.8 \\
Muslim & 18 & 9.9 \\
Protestant & 6 & 3.3 \\
Educational status & & \\
Unable to read and write & 37 & 20.3 \\
Read and write & 36 & 19.8 \\
Primary (I-8 grades) & 33 & 18.1 \\
Secondary (9-I2 grades) & 55 & 30.2 \\
College and above & 21 & 11.5 \\
Occupational status & & \\
Farmer & 19 & 10.4 \\
Merchant & 55 & 30.2 \\
Government employee & 27 & 14.8 \\
Daily labour & 12 & 6.6 \\
Student & 56 & \\
house wife & 13 & \\
\hline
\end{tabular}

\section{Associated variables and PP IUCD utilization}

Time of postpartum period of respondents was associated with PP IUCD utilization with $\mathrm{P}-$ value of 0.001 . Religious status of respondents is associated with PP IUCD utilization with P-value of 0.004. Educational status with $\mathrm{P}-\mathrm{value}$ of 0.037 and occupational status with $\mathrm{P}-$ value of 0.016 were associated with PP IUCD utilization (Table 2). Birth intervals with $\mathrm{P}$ - value of 0.009 , Time to get next pregnancy with $\mathrm{P}$ - value of 0.002 and PP contraceptive utilization with $\mathrm{P}$ of 0.042 were statistically associated variables that affect PP IUCD utilization (Table 3). As it was mentioned earlier, only 6 respondents $(3.3 \%)$ are currently using IUCD from giving birth to 9 months of their postpartum period. Of this, $50 \%$ of respondents reported that IUCD were inserted within $48 \mathrm{hrs}$ after giving birth at DTGH. $79 \%$ of respondents had heard IUCD and $72 \%$ were heard from health care givers. $41 \%$ respondents did not know one most commonly reported side effects of IUCD. 36\% respondents accepted to use IUCD in the future. Acceptances of IUCD with P of 0.004 and Reasons for refusal of IUCD with P value of 0.035 were statistically associated for utilization of PP IUCD (Table 4).

Table 2 Distribution of socio demographic variables with Chi square test for PP IUCD utilization from Nov. 10/2010 to Dec.25/2010 E.C at DTGH in Northwest Ethiopia

\begin{tabular}{|c|c|c|c|c|c|}
\hline \multirow[t]{2}{*}{ Variables } & \multicolumn{2}{|c|}{$\begin{array}{l}\text { PP IUCD } \\
\text { utilization }\end{array}$} & \multirow[t]{2}{*}{ Total } & \multirow[t]{2}{*}{ df } & \multirow{2}{*}{$\begin{array}{l}\text { chi- square test } \\
\text { P-value }\end{array}$} \\
\hline & Yes & No & & & \\
\hline Age $<25$ & & 30 & 30 & 3 & 0.105 \\
\hline $25-29$ & 3 & 84 & 87 & & \\
\hline $30-34$ & 3 & 28 & 31 & & \\
\hline 35 and above & & 34 & 34 & & \\
\hline $\begin{array}{l}\text { Time of pp } \\
\text { period* }\end{array}$ & Yes & No & Total & df & P-value \\
\hline within $48 \mathrm{hrs}$ & & 34 & 34 & 3 & 0.001 \\
\hline
\end{tabular}

Table continue

\begin{tabular}{|c|c|c|c|c|c|}
\hline \multirow[t]{2}{*}{ Variables } & \multicolumn{2}{|c|}{$\begin{array}{l}\text { PP IUCD } \\
\text { utilization }\end{array}$} & \multirow[t]{2}{*}{ Total } & \multirow[t]{2}{*}{ df } & \multirow{2}{*}{$\begin{array}{l}\text { chi- square test } \\
\text { P-value }\end{array}$} \\
\hline & Yes & No & & & \\
\hline $6-10$ weeks & & 80 & 80 & & \\
\hline 10-14 weeks & 6 & 39 & 45 & & \\
\hline >14week & & 23 & 23 & & \\
\hline Marital status & Yes & No & Total & df & P-value \\
\hline Married & 6 & 140 & 146 & 3 & 0.675 \\
\hline Divorce & & 15 & 15 & & \\
\hline Widowed & & 6 & 6 & & \\
\hline Single & & 15 & 15 & & \\
\hline $\begin{array}{l}\text { Religious } \\
\text { status* }\end{array}$ & Yes & No & Total & df & P-value \\
\hline Orthodox & 3 & 155 & 158 & 2 & 0.004 \\
\hline Muslim & 3 & 15 & 18 & & \\
\hline Protestant & & 6 & 6 & & \\
\hline $\begin{array}{l}\text { Educational } \\
\text { status* }\end{array}$ & Yes & No & Total & df & P-value \\
\hline $\begin{array}{l}\text { Unable to read and } \\
\text { write }\end{array}$ & & 37 & 37 & 4 & 0.037 \\
\hline Read and write & 3 & 33 & 36 & & \\
\hline $\begin{array}{l}\text { Primary (I-8 } \\
\text { grades) }\end{array}$ & 3 & 30 & 33 & & \\
\hline $\begin{array}{l}\text { Secondary (9-12 } \\
\text { grades) }\end{array}$ & & 55 & 55 & & \\
\hline College and above & & 21 & 21 & & \\
\hline $\begin{array}{l}\text { Occupational } \\
\text { status* }\end{array}$ & Yes & No & Total & df & p-value \\
\hline Farmer & & 19 & 19 & 5 & 0.016 \\
\hline Merchant & & 55 & 55 & & \\
\hline Government empl & oyee & 27 & 27 & & \\
\hline Daily labour & & 12 & 12 & & \\
\hline Student & & 13 & 13 & & \\
\hline House wife & 6 & 50 & 56 & & \\
\hline
\end{tabular}

This symbol $(*)$ indicates that the independent variable has effect on the outcome variable

Table 3 Reproductive history of respondents with chi square test for PP IUCD utilization from Nov.10/2010 to Dec.25/2010 E.C at DTGH in Northwest Ethiopia

\begin{tabular}{llllll}
\hline No of parity & Yes & No & Total & df & p-value \\
\hline P I & & 58 & 58 & 4 & 0.236 \\
P II & 3 & 55 & 58 & & \\
P III & 3 & 38 & $4 I$ & & \\
P IV & & 18 & 18 & & \\
PV and above & & 7 & 7 & & \\
No of alive & Yes & No & Total & df & p-value \\
children & & 3 & 3 & 4 & 0.238 \\
0 & & 58 & 58 & & \\
I & & & & & \\
\hline
\end{tabular}


Table continue

\begin{tabular}{|c|c|c|c|c|c|}
\hline No of parity & Yes & No & Total & df & p-value \\
\hline 2 & 3 & 60 & 63 & & \\
\hline 3 & 3 & 36 & 39 & & \\
\hline 4 and above & & 19 & 19 & & \\
\hline Birth interval* & Yes & No & Total & df & P-value \\
\hline Ist birth & & 58 & 58 & 2 & 0.009 \\
\hline $\mathrm{I}-3$ years & 6 & 66 & 72 & & \\
\hline$>3$ years & & 52 & 52 & & \\
\hline $\begin{array}{l}\text { Planning } \\
\text { of previous } \\
\text { pregnancy }\end{array}$ & Yes & No & Total & df & p-value \\
\hline Yes & 6 & 130 & 136 & I & 0.147 \\
\hline No & & 46 & 46 & & \\
\hline $\begin{array}{l}\text { Previous } \\
\text { contraceptive } \\
\text { use }\end{array}$ & Yes & No & Total & df & p-value \\
\hline Yes & 6 & 138 & 144 & 1 & 0.201 \\
\hline No & & 38 & 38 & & \\
\hline $\begin{array}{l}\text { Reasons for non- } \\
\text { users }\end{array}$ & Yes & No & Total & df & $\mathrm{P}$ - value \\
\hline Side effects & & 3 & 3 & 7 & 0.977 \\
\hline Lack of awareness & & 15 & 15 & & \\
\hline Husband refusal & & 6 & 6 & & \\
\hline Breast feeding & & 3 & 3 & & \\
\hline Menses not yet come & & 3 & 3 & & \\
\hline No method for me & & 3 & 3 & & \\
\hline Others & & 5 & 5 & & \\
\hline $\begin{array}{l}\text { Time to get } \\
\text { next pregnancy* }\end{array}$ & Yes & No & Total & df & p-value \\
\hline$<3$ yrs & & 18 & 18 & 4 & 0.002 \\
\hline$>=3 \mathrm{yrs}$ & & 69 & 69 & & \\
\hline Not decide to have & & 44 & 44 & & \\
\hline Infertile & & 3 & 3 & & \\
\hline Not yet decided & 6 & 42 & 48 & & \\
\hline $\begin{array}{l}\text { PP FP } \\
\text { counseling }\end{array}$ & Yes & No & Total & df & P-value \\
\hline Yes & 6 & $|4|$ & 147 & 1 & 0.224 \\
\hline No & & 35 & 35 & & \\
\hline $\begin{array}{l}\text { PP } \\
\text { contraceptive } \\
\text { utilization* }\end{array}$ & Yes & No & Total & df & p-value \\
\hline Yes & 6 & 84 & 90 & 2 & 0.042 \\
\hline No & & 86 & 86 & & \\
\hline Others & & 6 & 6 & & \\
\hline $\begin{array}{l}\text { Accessibility } \\
\text { options }\end{array}$ & Yes & No & Total & df & p-value \\
\hline Government HF & 6 & 154 & 160 & 3 & 0.837 \\
\hline Private clinic & & 13 & 13 & & \\
\hline Pharmacy & & 6 & 6 & & \\
\hline Others & & 3 & 3 & & \\
\hline
\end{tabular}

Table 4 Associated variables and PP IUCD utilization of respondents from Nov. I0/20I0 to Dec.25/20I0 E.C at DTGH, North West Ethiopia

\begin{tabular}{|c|c|c|c|c|c|}
\hline Heard PP IUCD & Yes & No & Total & df & p- value \\
\hline Yes & 6 & 138 & 144 & 1 & 0.201 \\
\hline No & & 38 & 38 & & \\
\hline Source of information & Yes & No & Total & Df & P-value \\
\hline Health care giver & 6 & 125 & $13 \mid$ & 3 & 0.491 \\
\hline Friends & & 23 & 23 & & \\
\hline Mas media & & 19 & 19 & & \\
\hline Others & & 9 & 9 & & \\
\hline Time of insertion* & Yes & No & Total & df & p-value \\
\hline No & & 176 & 176 & 2 & 0.0001 \\
\hline Within $48 \mathrm{hrs}$ & 3 & & 3 & & \\
\hline$>=6$ weeks & 3 & & 3 & & \\
\hline Side effects of IUCD* & Yes & No & Total & df & p-value \\
\hline Genital infection & 3 & 21 & 24 & 7 & 0.008 \\
\hline Irregular menses & & 9 & 9 & & \\
\hline Unusual discharge & & 5 & 5 & & \\
\hline Move to other parts & 3 & 18 & 21 & & \\
\hline Tear the uterus & & 10 & 10 & & \\
\hline Hidden in the uterus & & 9 & 9 & & \\
\hline I don't know & & 74 & 74 & & \\
\hline Others & & 30 & 30 & & \\
\hline Acceptance of IUCD* & Yes & No & Total & df & P-value \\
\hline Yes & 6 & 63 & 69 & 2 & 0.004 \\
\hline No & & 113 & 113 & & \\
\hline $\begin{array}{l}\text { Reasons for refusal of } \\
\text { IUCD* }\end{array}$ & Yes & No & Total & df & p- value \\
\hline Accepted & 6 & 63 & 69 & 5 & 0.035 \\
\hline Afraid of side effects & & 39 & 39 & & \\
\hline Need pregnancy recently & & 9 & 9 & & \\
\hline Misconceptions & & 12 & 12 & & \\
\hline I do not know & & 26 & 26 & & \\
\hline Others & & 27 & 27 & & \\
\hline
\end{tabular}

\section{Discussion}

The prevalence of this study is slightly higher as compared to EDHS 2016 report (2\%). This might be due to the difference in data collection techniques since EDHS were made survey at community level where as the collected data in this study was at facility level with small sample size. ${ }^{5}$ In this study, PP IUCD utilization is extremely low $(1.65 \%)$ as compared to a study conducted in Sidama Zone in Ethiopia which showed that PP IUCD contraceptive device use within 48 hours of delivery was $21.6 \%$. This study revealed that $37.9 \%$ respondents were interested in using IUCD in the future while $38 \%$ of the respondents were interested in using PPIUD in Sidama zone which is fairly similar to this study. ${ }^{11}$ The prevalence of this study is also lower as compared to a study conducted in Kenya at Mbagathi and Mama Lucy Kibaki Hospitals which was 7.9\%. ${ }^{1}$ This might be the difference in socio demographic character of respondents. The 
prevalence of this study is also lower than a study conducted in United States revealed that $70 \%$ of participants chose a LARC method and $11 \%$ of respondents chose copper bearing IUD. Surprisingly, among the adolescents aged $14-20$ years, $62 \%$ chose a LARC method. ${ }^{12}$ This is quite different in most regions of Ethiopia in which they are still utilized short acting hormonal contraceptives commonly Injectable. The possible justification might be due to socio-cultural, economic and demographic characteristics of study participants.

Eight seven (47.9\%) respondents whose ages are 25-29 years are currently using one modern contraceptive method during their postpartum period. This utilization is almost similar to contraceptive prevalence rate (CPR) among married women increases with age, peaking at age $25-29(41 \%){ }^{5}$ This could be as a result of most mothers are commonly get marriage in this age group and mothers wish to be around this age group even if they are older and there is no method to ascertain the reported data. In this study, $144(79.12 \%)$ respondents have ever heard about IUCD which is slightly lower as compared to a situation analysis report in Ethiopia which showed that about $96 \%$ of the women interviewed have ever heard about FP. This study revealed that women in Amhara were more likely to know about IUCDs than women in the other regions. ${ }^{8}$ This difference might be due to the study variable which is specifically for IUCD only but not for all FP methods. In this study, acceptance rate of copper bearing IUCD among respondents is $37.91 \%$. The rest were refused to take it. Majority of them $(34.5 \%)$ among refusers were afraid of side effects, $23 \%$ of them did not know the reason for refusal, $10.62 \%$ have had misconceptions and $23.89 \%$ have had different reasons for refusal such as hidden itself, move to upward to brain, uterine cancer, source of divorce due to painful sexual practice and abnormal discharge. Almost the same is true for other studies in which barriers or factors that hindered women from using IUD were myths, rumours and misconceptions including perceived side effect persist in the region and they limited the uptake of IUD. ${ }^{1}$ Probability sampling technique were considered to be the strength of this study to generalize the findings to the study population and barriers and associated factors were identified and well communicated. However, cross section study design did not show us real cause and effect relationship.

\section{Conclusion}

PP IUCD utilization among mothers who have delivered in Debre Tabor General Hospital is 3.3 percent. Even though the national contraceptive prevalence rate (CPR) is increasing across regions, especially in Amhara region, utilization of long term reversible contraceptive utilization in Debre Tabor General Hospital is low as compared to other studies. In this study, the acceptance level (37.91\%) and PP IUCD utilization (3.3\%) were estimated and showed us major differences. It would be associated with the failure of exploring the knowledge, attitude, and misperceptions of side effects and other unspeakable reasons associated with IUCD utilization in the community. It is better to correct misconceptions and rumors through effective family planning counseling and made continuous supportive supervision. Therefore, responsible bodies should focus on specific interventions related to associate factors at the facility and community level. We recommend other researchers to research the perception of the community on IUCD utilization using mixed-method approaches and advanced statistical analysis.

\section{Declarations}

\section{Ethics and consent to participate}

Ethical clearance and permission was obtained from Debre Tabor University Research and Ethical Review Committee and Debre Tabor
General Hospital Administrative office. Written consent to participate was obtained from the postpartum mothers and parents of the minors under the age of 16 on voluntary basis. They were informed to withdraw or continue in the study at any time after the risk and the benefit of the study to participant were explained by data collectors. Finally, confidentiality of information provided by data collectors were also protected by making the data collection procedure anonymous.

\section{Consent for publication}

Written informed consent for publication was obtained from all interviewed respondents or their parent in the case of children under 18.

\section{Availability of dataset and materials}

We authors confirm that the remaining raw data will be available as per the request for those wishing to use it for scientific purpose.

\section{Competing interests}

We authors declared that conflict of interest for this review will never exist.

\section{Funding}

No funding was obtained for this study

\section{Author's contribution}

$\mathrm{HH}$ initiated the conception of this study, conducted literature review and analyses, wrote the earlier draft of the manuscript and finalized the manuscript. DT supervised with constructive comments starting from the conception to comments up to the preparation of the final manuscript. WN supervised with constructive comments starting from the conception to comments up to the preparation of the final manuscript. SB directed the design, quality assessment and supervised the review and commented on the final drafts of the manuscripts. All authors have read and approved the final manuscript to be sent for publication.

\section{Acknowledgements}

Our deepest appreciation also go to Debre Tabor University College Health Science Department of Midwifery for giving this chance and facilitating our research program and those individuals who are interested in helping me from title selection to the completion of this research paper. Lastly but not the least, I am glad to acknowledge study participants, data collector, supervisors and DTGH administrators for their cooperation for this research work.

\section{Conflicts of interest}

All authors declared conflict of interest was not existed.

\section{References}

1. Wangari F. Intrauterine Device Uptake Among Women Seeking Family Planning Services At Mbagathi And Mama Lucy Kibaki Hospitals In Nairobi County. Kenya, 2015. p. 42-47.

2. Long-Acting Reversible Contraception (LARC): IUD and Implant. 2016.

3. Program Learning for Postpartum Intrauterine Contraceptive Device (PPIUCD) Integration with Maternal Health Services. USAID, MCHIP Guidance for PPIUCD. Cochrane Database Systematic Review. 2010;5:1.

4. MOH. National Family Planning guide line. Addis Ababa, Ethiopia, 2015. 
5. Central Statistical Agency, Ethiopia Demographic and Health Survey. Addis Ababa, Ethiopia and Calverton, MD., USA. 2016.

6. Ministry of Health and Family Welfare, Government of India: Postpartum IUCD Reference Manual Planning Division, Nirman Bhawan. New Delhi-110011, 2010.

7. Grimes D. Immediate post-partum insertion of intrauterine devices. The Cochrane Database of Systematic Reviews. 2003;1.

8. Community Based Family Planning, Including Long Acting Contraceptive Services At Selected Health Centers And Their Satellite Health Posts In Four Regions Of Ethiopia: Family Planning Situational Analysis Report in Ethiopia. 2015.

9. Post Partum Intrauterine Contraceptive Device (PPIUCD), Participant's Handout, Federal Democratic Republic of Ethiopia, Ministry of Health. 2013.

10. Getachew A. Assessment of postpartum contraceptive adoption and associated factors in Butajira Health and Demographic Surveillance Site (HDSS), in Southern Ethiopia. AAU, Jun, 2015.
11. Bezabih L. Utilization of Immediate Post-Partum Intra Uterine Contraceptive Device and Associated Factors among Mothers Delivered at Public Health Facilities of Sidama Zone, South Ethiopia. Journal of Pregnancy and Child Health. 2017;4:3.

12. Renee Mestad, Gina Secura, Jenifer E Allsworth, et al, Acceptance of long-acting reversible contraceptive methods by adolescent participants in the Contraceptive CHOICE Project. Contraception. 2011;84(1):493498.

13. Rukiya A. Acceptability And Safety Of Postpartum Intrauterine Contraceptive Device Among Parturients At Muhimbili National Hospital. Tanzania, 2012.

14. Suchitra A. Factors Affecting Acceptance of Intrauterine Device (IUD) Among Rural Women of Hirebagewadi, Belgaum. IOSR Journal of Nursing and Health Science (IOSR-JNHS). 2014;2(1):37-52. 